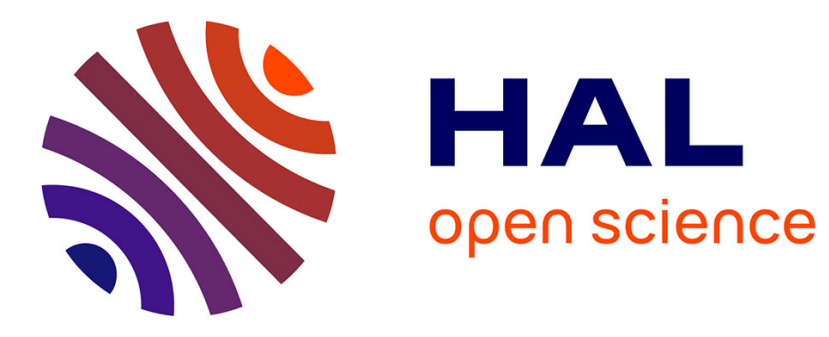

\title{
Dynamin 2 mutations cause sporadic centronuclear myopathy with neonatal onset
}

\author{
Marc Bitoun, Jorge Alfredo Bevilacqua, Bernard Prudhon, Svetlana \\ Maugenre, Ana Lia Taratuto, Soledad Monges, Fabiana Lubieniecki, Claude \\ Cances, Emmanuelle Uro-Coste, Michèle Mayer, et al.
}

\section{To cite this version:}

Marc Bitoun, Jorge Alfredo Bevilacqua, Bernard Prudhon, Svetlana Maugenre, Ana Lia Taratuto, et al.. Dynamin 2 mutations cause sporadic centronuclear myopathy with neonatal onset. Annals of Neurology, 2007, 62 (6), pp.666-670. 10.1002/ana.21235 . hal-02448610

\section{HAL Id: hal-02448610 https://hal.science/hal-02448610}

Submitted on 22 Jan 2020

HAL is a multi-disciplinary open access archive for the deposit and dissemination of scientific research documents, whether they are published or not. The documents may come from teaching and research institutions in France or abroad, or from public or private research centers.
L'archive ouverte pluridisciplinaire HAL, est destinée au dépôt et à la diffusion de documents scientifiques de niveau recherche, publiés ou non, émanant des établissements d'enseignement et de recherche français ou étrangers, des laboratoires publics ou privés. 


\section{Dynamin 2 mutations cause sporadic centronuclear myopathy with neonatal onset}

Marc Bitoun $(\mathrm{PhD})^{1,2}$, Jorge A. Bevilacqua $(\mathrm{MD}, \mathrm{PhD})^{1,3}$, Bernard Prudhon ${ }^{1,2}$, Svetlana Maugenre $^{1,2}$, Ana Lia Taratuto (MD, PhD) $)^{4,5}$, Soledad Monges (MD) ${ }^{4}$, Fabiana Lubieniecki $(\mathrm{MD})^{4}$, Claude Cances (MD) ${ }^{6}$, Emmanuelle Uro-Coste $(\mathrm{MD})^{7}$, Michèle Mayer (MD) ${ }^{8}$, Michel Fardeau (MD) ${ }^{1,2,9}$, Norma B. Romero (MD, PhD) ${ }^{1,2,9}$, Pascale Guicheney $(\mathrm{PhD})^{1,2,9}$

1. INSERM, U582, Institut de Myologie, Paris, France.

2. Université Pierre et Marie Curie-Paris6, UMR S582, IFR14, Paris, France.

3. Departamento de Neurología y Neurocirugía, HCUCH and Instituto de Ciencias Biomédicas Universidad de Chile, Santiago, Chile.

4. Hospital Nacional de Pediatría J.P. Garrahan, Buenos Aires, Argentina.

5. Instituto de Investigaciones Neurologicas, FLENI: Departamento de Neuropatologia, Buenos Aires, Argentina.

6. Hôpital des Enfants, Département de Pédiatrie, Toulouse, France.

7. Service d'Anatomie Pathologique, CHU Rangueil, Toulouse, France.

8. Hôpital Armand Trousseau, Service de Neuropédiatrie, Consultation Maladies Neuromusculaires, Paris, France.

9. AP-HP, Groupe Hospitalier Pitié-Salpêtrière, Paris, France.

Text: 1477 words

Title: 77 characters

Running head: 37 characters

Abstract: 96 words

Table: 1 
Color figures: 2

Number of references: 11

Running title: Dynamin2 mutations cause neonatal CNM

\section{Corresponding Author:}

Dr. Pascale Guicheney, Inserm U582, Institut de Myologie, Groupe Hospitalier PitiéSalpêtrière, 75013, Paris, France.

E-mail: p.guicheney@myologie.chups.jussieu.fr

Tel : 33 (0) 1.42.16.57.35

Fax: $33(0) 1.42 .16 .57 .00$

Disclosure: The authors have reported no conflicts of interest.

Acknowledgements. We thank the patients and their families for their participation in this study, Dr M Lucero for assistance, Dr T Stojkovic and Dr K Flaningan for helpful advices, the Institut National de la Santé et de la Recherche Médicale (INSERM), the Association Française contre les Myopathies (AFM), and the Programme of Collaboration ECOS-SECyT $\left(\mathrm{N}^{\circ} \mathrm{A} 02 \mathrm{~S} 02\right)$ for financial support. Jorge A. Bevilacqua was supported by the Programme Alban, the European Union Programme of High Level Scholarships for Latin America, scholarship No.E04E028343CL. Marc Bitoun was a recipient of an INSERM fellowship. 


\begin{abstract}
We report four heterozygous Dynamin 2 (DNM2) mutations in 5 CNM patients, aged of 1 to 15 years. They all presented with neonatal hypotonia with weak suckling. Thereafter, their phenotype progressively improved. All patients demonstrated muscle weakness prominent in the lower limbs and most of them also presented with facial weakness, open mouth, arched palate, ptosis and ophthalmoparesis. Electrophysiology only showed myopathic changes and muscle biopsies showed central nuclei and type 1 fibre hypotrophy and predominance. Our results expand the phenotypic spectrum of DNM2-related CNM from the classical mild form to the more severe neonatal phenotype.
\end{abstract}

Keywords: Dynamin 2, Centronuclear Myopathy, Autosomal dominant inheritance. Neonatal onset. 


\section{Introduction}

The centronuclear myopathies ${ }^{1}$ are a heterogeneous group of rare neuromuscular disorders including "Myotubular myopathy" for the severe X-linked recessive form (XLMTM) due to myotubularin mutations ${ }^{2}$ and "Centronuclear myopathy" (CNM) for the autosomal forms. Autosomal CNMs comprise a wide spectrum of phenotypes, ranging from severe neonatal to mild late-onset familial forms. The most frequent clinical features are delayed motor milestones, facial and generalised muscle weakness, ptosis and ophthalmoparesis or ophthalmoplegia ${ }^{3,4}$. The most prominent histopathological features consist of a high frequency of centrally located nuclei in the muscle fibres and predominance and hypotrophy of type 1 fibres $3,4,5$.

We identified the first mutations responsible for autosomal dominant (AD) CNM in the DNM2 gene encoding dynamin $2(\mathrm{DNM} 2)^{6}$, a large GTPase that was mainly implicated in endocytosis and membrane trafficking ${ }^{7,8}$. These first 4 heterozygous mutations were all restricted to the middle domain of the protein and were identified in families or sporadic cases mostly showing mild, late onset $\mathrm{CNM}^{6}$. Independently, 3 heterozygous mutations in the Pleckstrin Homology $(\mathrm{PH})$ domain of DNM2 have also been reported in dominant intermediate Charcot-Marie-Tooth disease type B (DI-CMTB) ${ }^{9}$.

Here, we report five patients with four novel heterozygous mutations in the $\mathrm{PH}$ domain of the DNM2 leading to sporadic CNM. In contrast to the previously reported DNM2 mutations, these four mutations are associated with a neonatal onset and a more severe phenotype. 


\section{Methods}

DNM2 sequencing. The genomic sequence of DNM2 (NT_011295) was used to design intronic primers to amplify the 22 DNM2 exons, including exons 10 bis and 13bis. Polymerase chain reactions and sequencing were done as previously described ${ }^{6}$.

Clinical and morphological studies. The clinical data of the five patients were retrospectively reviewed and were summarized in the Table 1 . Motor and sensory nerve conduction studies were performed using standard procedure. Standard histochemical techniques were performed on deltoid or quadriceps muscle biopsies from the five patients (Hematein-Eosin, Myosin Adenosine Triphosphatase preincubated at $\mathrm{pH} 9.4$ or 4.2, and Nicotinamide Adenine Dinucleotide-Tetrazolium Reductase staining). Digital photographs were obtained with a Zeiss AxioCam HRc attached to a Zeiss Axioplan Bright Field Microscope. For patients 1, 2 and 3, muscle samples were also fixed in $2.5 \%$ glutaraldehyde and embedded in Polybed 812. Ultrathin sections were stained with uranyl acetate and lead citrate (Reynolds) and examined under a Zeiss 109 electron microscope. 


\section{Results}

DNM2 screening. We identified 4 heterozygous mutations in 5 CNM patients by sequencing of the coding sequence of $D N M 2$ gene. The mutations were all located in exon 16: a missense mutation (c.1852G>A) changing alanine 618 to threonine (p.A618T) in patient 1, a missense mutation (c.1856C > T) changing serine 619 to leucine (p.S619L) in patients 2 and 3, a missense mutation (c.1856C >G) changing serine 619 to tryptophan (p.S619W) in patient 4, and a three base pairs deletion (c.1873_1875delGTC) inducing deletion of the valine 625 (p.V625del) in patient 5. Sequences of DNA samples from parents, available for patients 1, 2, 3 and 5, were normal and the paternity was confirmed, indicating de novo mutations. The four mutations were not found in 100 unrelated healthy control subjects. All mutations were detected in 3 conserved amino-acids located in the PH domain of DNM2 (Figure 1A).

Clinical data. For the 5 patients, there was no family history of neuromuscular disorder. The clinical features are summarized in Table 1. The pregnancies were normal except for the mother of patient 5 affected by pregnancy-induced hypertension. The 5 patients presented with neonatal hypotonia. None needed respiratory support although three transiently received oxygen in neonatal period. They all had weak suckling and three required nasogastric tube for feeding. Three patients presented with marked facial weakness, open mouth and arched palate in early childhood and four have ptosis and ophthalmoparesis (Figure 1). Motor milestones were delayed in three patients. Patient 3 was not able to sit, nor control his head or lift his legs at the age of 1 year and patient 2 walked at the age of 28 months but only with aid. Only patients 4 and 5 reached independent ambulation at a normal age. All demonstrated generalized muscle weakness prominent in lower limbs, and distal limb muscles were more severely affected than proximal muscles. Serum CK level was slightly increased only in 
patient 3. Neutrophil counts available for patients 1, 2 and 3 were within the normal range for age. There were no cardiac abnormalities on electrocardiogram and echocardiography in patients 2 to 5, while mild apex dilatation was reported in patient 1 . Patients 1,2 and 3 have no respiratory involvement but patients 4 and 5 developed a restrictive respiratory syndrome at the age of 10 and 7 years, respectively.

Patient 2 has been studied twice by electromyography (EMG) and nerve conduction velocities $(\mathrm{NCV})$ at the ages of 4 months and 2 years. These showed myopathic changes, normal peroneal and median NCV and normal CMAP amplitudes. Patient 3 was similarly evaluated at 11 days after birth. EMG revealed a myopathic pattern and motor and sensory nerve conduction studies were normal (Table 1). Patient 5 also showed a myopathic pattern on EMG at the age of 5 years and had normal motor NCV.

Morphological data. Quadriceps or deltoid muscle biopsies performed from the ages 5 months to 8 years were available for the 5 patients. All biopsies showed predominance and hypotrophy of type 1 fibres with central nuclei (Figure 2). Percentage of fibres with central nuclei was $50 \%, 41 \%, 44 \%$, and 3\%, respectively for patients $1,2,3$, and 5 . NADH-TR reaction occasionally showed increased oxidative activity around central nuclei. A radial arrangement of sarcoplasmic strands around the central nuclei was observed in only a few fibers, mainly in patient 2. In the quadriceps biopsy from patient 3 performed at the age of 5 months, no radial arrangement of sarcoplasmic strands was observed, even by electron microscopy. Endomysial fibrosis was observed in the biopsies from patients 1 and 2 (Figure 2), but there was no evidence of necrosis or regeneration in any of the biopsies. 


\section{Discussion}

In the present study, we identified four novel heterozygous mutations in the Pleckstrin Homology domain of the Dynamin 2 in young CNM patients who presented with a more severe phenotype than is typical in autosomal dominant CNM.

The four girls and the boy presently described, shared some XLMTM features ${ }^{10,11}$ such as severe generalized hypotonia and muscle weakness at birth, ophthalmoparesis and facial weakness, and normal serum creatine kinase levels, nerve conduction velocities and cardiac function. However, in these DNM2-related CNM patients, there were no decreased foetal movements, premature births or long periods of respiratory insufficiency after birth, while these are often associated with XLMTM. Finally, DNM2-related neonatal CNM is associated with a relatively good prognosis in comparison with XLMTM in which most of patients die during the first yearsof life from respiratory failure. In our series, only the boy was still very weak at the age of one year while the girls progressively became stronger. However, the two oldest patients developed a restrictive respiratory syndrome at the age of 7 and 10 years and lost deep tendon reflexes.

In the presently described patients, the classical morphological abnormalities described in late-onset CNM patients, especially concerning the radial arrangement of sarcoplasmic strands, were less pronounced. One can hypothesise that their scarcity is probably linked to the young age of the patients. However, in spite of the diagnosis difficulties, association of central nuclei and type 1 fibre predominance and hypotrophy with the described clinical findings allowed us to identify a group of 7 CNM-patients and we found DNM2 mutations in five of them. These results show a genetic heterogeneity in the autosomal neonatal CNM with a high frequency of mutation of the DNM2 gene and may enable a better selection for direct genetic testing. 
Interestingly, three other DNM2 mutations in the PH domain have been reported in dominant intermediate Charcot-Marie-Tooth disease type B (DI-CMTB) ${ }^{9}$, which raises the possibility that these phenotypes may overlap. Previously, we found mild signs of axonal sensorimotor neuropathy in addition to predominant myopathic changes in 4 of 10 patients affected by mild, late-onset CNM harbouring mutations in the middle domain of DNM2 ${ }^{5}$. In the young patients reported here, the available electrophysiological data only show myopathic changes. It would be certainly of interest to follow the evolution of neurophysiological parameters in these patients in order to determine a possible progressive peripheral nerve involvement.

In conclusion, we report the first mutations in the PH domain of DNM2 in 5 patients with a neonatal onset and relatively severe CNM, with the development of a restrictive respiratory syndrome at the end of the first decade. These heterozygous de novo mutations enlarge the spectrum of DNM2-related CNM from the classical mild form to include the neonatal phenotype, overlapping with the mild end of the spectrum of XLMTM but with a better prognosis. Our findings show that DNM2 gene should be considered in severe sporadic neonatal CNM without MTM1 mutations in whom inheritance is impossible to predict. 


\section{References}

1. Spiro AJ, Shy GM, Gonatas NK. Myotubular myopathy. Persistence of fetal muscle in an adolescent boy. Arch Neurol 1966;14:1-14.

2. Laporte J, Hu LJ, Kretz C, et al. A gene mutated in X-linked myotubular myopathy defines a new putative tyrosine phosphatase family conserved in yeast. Nat Genet 1996;13:175-182.

3. Fardeau M, Tomé F. Congenital myopathies. In: Engel AG, Franzini-Armstrong C, eds. Myology, 2nd ed. New York: MacGraw Hill, 1994:1500-1504.

4. Jeannet PY, Bassez G, Eymard B, et al. Clinical and histologic findings in autosomal centronuclear myopathy. Neurology 2004;62:1484-1490.

5. Fischer D, Herasse M, Bitoun M, et al. Characterization of the muscle involvement in dynamin 2 related centronuclear myopathy. Brain 2006;129:1463-1469.

6. Bitoun M, Maugenre S, Jeannet P, et al. Mutations in dynamin 2 cause dominant Centronuclear Myopathy. Nat Genet 2005;37:1207-1209.

7. Jones SM, Howell KE, Henley JR, et al. Role of dynamin in the formation of transport vesicles from the trans-Golgi network. Science 1998;279:573-577.

8. Praefcke GJ, McMahon HT. The dynamin superfamily: universal membrane tubulation and fission molecules? Nat Rev Mol Cell Biol 2004;5:133-147. 
9. Züchner S, Noureddine M, Kennerson M, et al. Mutations in the pleckstrin homology domain of dynamin 2 cause dominant intermediate Charcot-Marie-Tooth disease. Nat Genet 2005;37:289-294.

10. Wallgren-Pettersson C, Clarke A, Samson F, et al. The myotubular myopathies:

differential diagnosis of the $\mathrm{X}$ linked recessive, autosomal dominant, and autosomal recessive forms and present state of DNA studies. Med Genet 1995;32:673-679.

11. Pierson CR, Tomczak K, Agrawal P, et al. X-linked myotubular and centronuclear myopathies. J Neuropathol Exp Neurol 2005;64:555-564. 


\section{Legends}

\section{Table 1: Summary of clinical data}

F: Female; M: Male, yrs: years, mo: months. -: no information. NVC: nerve conduction velocities, CMAP: compound muscle action potential, SNAP: sensory nerve action potential.

\section{Figure 1: Clinical features of patients 1, 2 and 3 with early onset CNM with DNM2 mutations in the PH domain.}

A. Position of the DNM2 mutations identified in CNM patients. Mutations are specified on the predicted protein structure including a tripartite GTPase domain (GTPase), a middle domain (Middle), a Pleckstrin Homology domain (PH), a GTPase effector domain (GED) and a Proline rich domain (PRD). The new mutations identified in CNM patients are indicated in red and the already reported mutations in CNM and CMT patients are indicated blue and green, respectively. All the variants were numbered according to the same isoform, isoform 1 (Accession number: NP_001005360) since this isoform, which includes the four amino-acids GEIL at positions 516-519 encoded by exon 13bis, is the major one in human brain, muscle, and primary cultured myoblasts. B: Patient 1 (mutation p.A618T) at the age of 5 years. C: Patient 2 (mutation p.S619L) at the age of 2 years. D: patient 3 (mutation p.S619L) at the age of 6 months. All patients had generalized hypotonia, bilateral facial weakness, ptosis and open mouth. A severe ophthalmoparesis was present in patient 2 (note position of left eye with an internal deviation on top left panel). Patient 1 had equinovarus and pes cavus.

\section{Figure 2: Histological features in DNM2-related CNM patient}

Hematein-Eosin staining (A,B,C,D), ATPase preincubated at pH 9.4 (E,G,H) or pH 4.2 (F) staining and Nicotinamide Adenine Dinucleotide-Tetrazolium Reductase (I,J,K,L,N) staining 
on muscle biopsies from patients 1 (deltoid biopsy at the age of 5 years), 2 (quadriceps biopsy at the age of 1 year), 5 (quadriceps biopsy at the age of 2 years) and in a deltoid muscle biopsy performed at the age of 2 years in one healthy patient (control). Representative fields of DNM2-related CNM patients showing internal nuclei (A,B,C), type 1 fibre predominance and hypotrophy $(\mathrm{E}, \mathrm{F}, \mathrm{G})$ and distorted myofibrillary structure $(\mathrm{I}, \mathrm{J}, \mathrm{K})$ in comparison with control (D,H,L). M: electron microscopy for patient 1 showed an halo devoid of organelles around central nucleus and an appearance of radiating sarcoplasmic strands. $\mathrm{N}$ : enlargement of NADH-TR staining for patient 2 focused on one fiber with radiating sarcoplasmic strands. 
Table 1: Summary of clinical data

\begin{tabular}{|c|c|c|c|c|c|}
\hline & patient 1 & patient 2 & patient 3 & patient 4 & patient 5 \\
\hline Sex / Origin & F / Argentina & F/ Argentina & M / Argentina & F/ France & F/ France \\
\hline Mutation & p.A618T & p.S619L & p.S619L & p.S619W & p.V625del \\
\hline Age at last examination & $6.5 \mathrm{yrs}$ & $3.5 \mathrm{yrs}$ & $1 \mathrm{yr}$ & $15 \mathrm{yrs}$ & $7 \mathrm{yrs}$ \\
\hline \multicolumn{6}{|l|}{ At birth } \\
\hline O2 therapy/days & Yes, 14 days & Yes, 4 days & Yes, 4 days & No & No \\
\hline feeding/nasogastric tube & Yes, few days & Yes, 15 days & yes, up to 1 year & No & No \\
\hline \multicolumn{6}{|l|}{ Motor development } \\
\hline head control & $12 \mathrm{mo}$ & $6 \mathrm{mo}$ & not acquired at 1 year & $2 \mathrm{mo}$ & $4 \mathrm{mo}$ \\
\hline age sitting & $24 \mathrm{mo}$ & $8 \mathrm{mo}$ & not acquired at 1 year & $7 \mathrm{mo}$ & $9 \mathrm{mo}$ \\
\hline age ambulation & $30 \mathrm{mo}$ & $28 \mathrm{mo}$ & not acquired at 1 year & $14 \mathrm{mo}$ & $13 \mathrm{mo}$ \\
\hline with/without aid & without aid but orthoses & with aid only (ongoing) & & without aid & without aid \\
\hline \multicolumn{6}{|l|}{ Other parameters } \\
\hline open mouth / arched palate & Yes / Yes & Yes / Yes & Yes / Yes & No / No & $-1-$ \\
\hline ptosis & Yes & Yes & Yes & No & Yes \\
\hline ophthalmoparesis & Yes, slight & Yes & Yes & No & Yes \\
\hline pes cavus & Yes & No & No & Yes & No \\
\hline scoliosis & Yes & Yes at 2 yrs and $8 \mathrm{mo}$ & No & No & No \\
\hline contractures & Yes, Achills tendon & Yes, Achilles tendon & Yes, Achilles tendon & Yes, Achilles tendon & No \\
\hline hyperlaxity & & Yes & Yes & No & Yes \\
\hline CK (UI/l) & 92 & 80 & 476 & & 37 \\
\hline White blood cells & $6700 / \mathrm{mm} 3$ & $7700 / \mathrm{mm} 3$ & $13300 / \mathrm{mm} 3$ & & \\
\hline Neutrophil counts/age & $54 \%$ at 5 yrs and $9 \mathrm{mo}$ & $45 \%$ at $11 \mathrm{mo}$ & $30 \%$ at $5 \mathrm{mo}$ & & \\
\hline cardiac function & $\begin{array}{l}\text { mild apex dilatation } \\
\text { ventricular function normal }\end{array}$ & - & normal & normal & normal \\
\hline $\operatorname{NCV}(\mathbf{m} / \mathbf{s})$ & - & & & - & \\
\hline Left Peroneal & & $48.7(4 \mathrm{mo})$ and $60(2 \mathrm{yrs})$ & & & 64.5 (3yrs) \\
\hline Left Median motor & & 47.7 (4 mo) and 51.9 (2 yrs) & & & 72.1 (3yrs) \\
\hline Left Tibial & & & 22.4 (11 days) & & \\
\hline Left Ulnar motor & & & 32.6 (11 days) & & \\
\hline left Median antisensory & & & 32.1 & & \\
\hline CMAP (mV) & - & & - & - & \\
\hline Peroneal & & $9.9(4 \mathrm{mo})$ and $6.8(2 \mathrm{yrs})$ & & & \\
\hline Median & & $7.8(4 \mathrm{mo})$ and $4.8(2 \mathrm{yrs})$ & & & \\
\hline SNAP $(\boldsymbol{\mu V})$ & & & 3.3 & & \\
\hline
\end{tabular}


present (2 yrs) absent (8 yrs)

present (3 yrs) absent (7 yrs) 

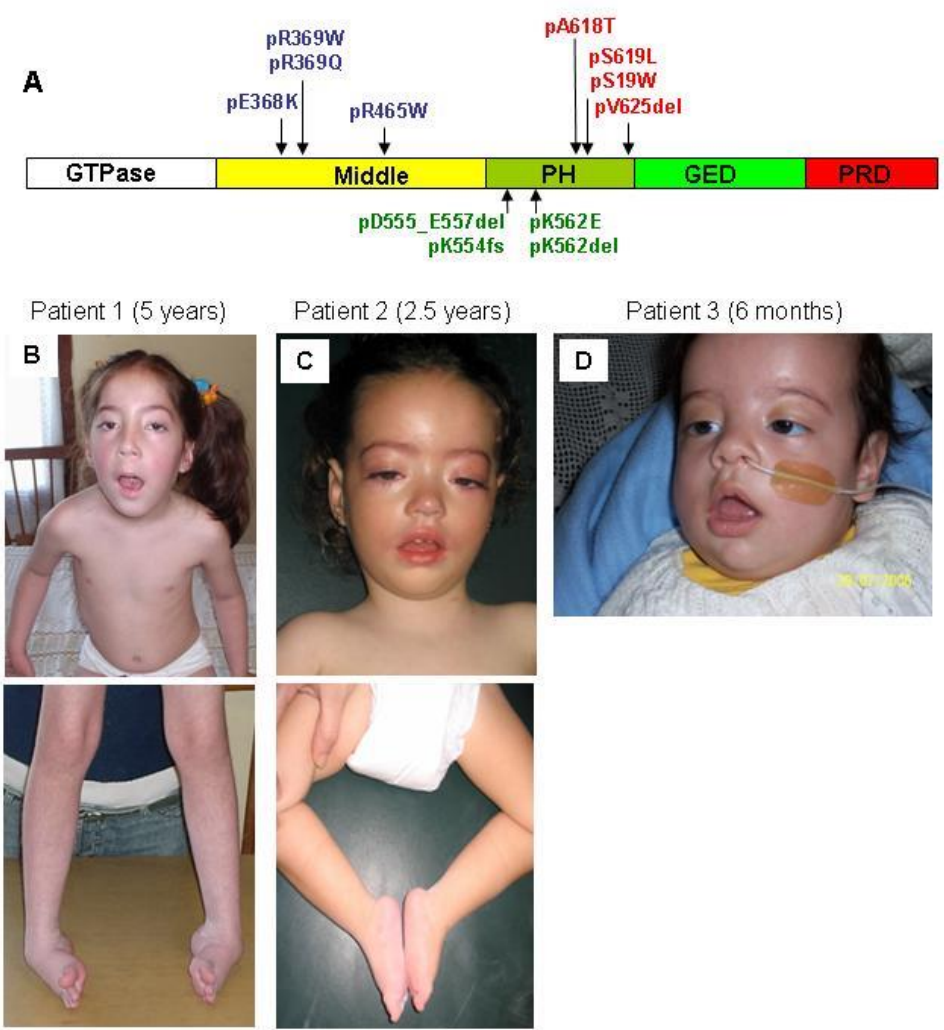

Patient 3 (6 months)

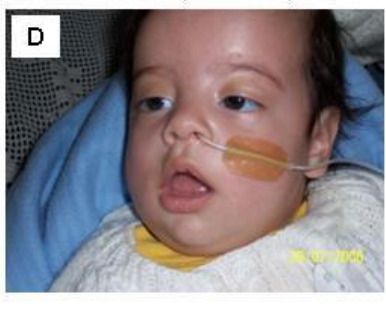

Figure 1 


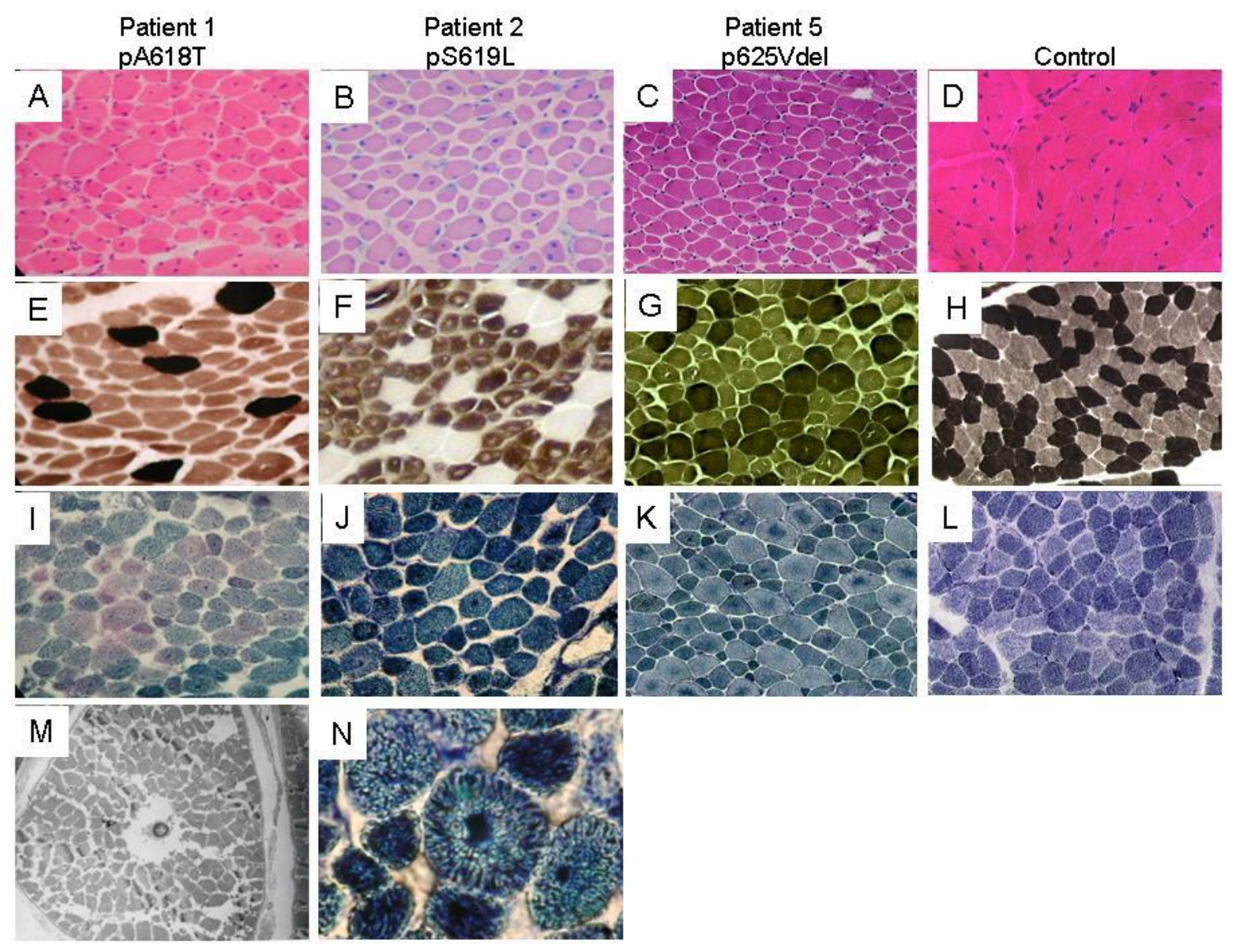

Figure 2 